\title{
Crystal Orientation Dependent Oxidation Modes at the Buried Graphene-Cu Interface
}

\author{
Philipp Braeuninger-Weimer,* Oliver J. Burton, Patrick Zeller, Matteo Amati, Luca Gregoratti, \\ Robert S. Weatherup, and Stephan Hofmann*
}

Cite This: Chem. Mater. 2020, 32, 7766-7776

Read Online

\section{ACCESS \\ Џlll Metrics \& More \\ Article Recommendations \\ Supporting Information}

ABSTRACT: We combine spatially resolved scanning photoelectron spectroscopy with confocal Raman and optical microscopy to reveal how the oxidation of the buried graphene$\mathrm{Cu}$ interface relates to the $\mathrm{Cu}$ crystallographic orientation. We analyze over 100 different graphene covered $\mathrm{Cu}$ (high and low index) orientations exposed to air for 2 years. Four general oxidation modes are observed that can be mapped as regions onto the polar plot of $\mathrm{Cu}$ surface orientations. These modes are (1) complete, (2) irregular, (3) inhibited, and (4) enhanced wrinkle interface oxidation. We present a comprehensive characterization of these modes, consider the underlying mechanisms, compare air and water mediated oxidation, and discuss this in the context of the diverse prior literature in this area. This understanding incorporates effects from across the wide parameter space of $2 \mathrm{D}$ material interface engineering, relevant to key challenges in their emerging applications, ranging from scalable transfer to electronic contacts, encapsulation, and corrosion protection.

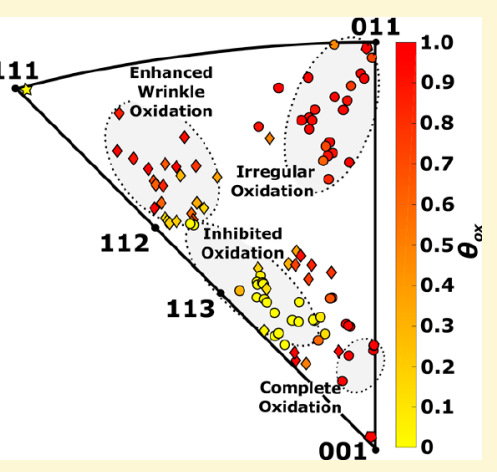

\section{INTRODUCTION}

Two dimensional layered materials have been extensively studied over the last 15 years. More recently, the importance of interface effects between 2D layers and 3D materials has gained increasing prominence. Graphene-substrate interactions play a governing role in the physical, electrical, and chemical characteristics of a graphene layer. Prominent examples include the graphene transfer from a catalyst, ${ }^{1-5}$ electronic contacts, ${ }^{6-8}$ encapsulation of graphene device channels, $^{9-13}$ diffusion barriers for $\mathrm{Cu}$ interconnects, ${ }^{14,15}$ and corrosion protection effects that $2 \mathrm{D}$ materials can provide for 3D materials. ${ }^{16,17}$ Depending on the device integration pathway and the nature of the application, precise tuning of the interaction strength between $2 \mathrm{D}$ and $3 \mathrm{D}$ materials is required. As such, intercalation at the graphene-metal interface has been widely studied as a means of tuning interaction strength. ${ }^{18-22}$ Selective oxidation of the metal surface beneath graphene has been introduced as a route to weaken interaction and facilitate graphene transfer with minimized damage and contamination. ${ }^{4,23-25}$ Alternatively, for applications where the $2 \mathrm{D}$ layer functions as a corrosion inhibitor, ${ }^{17,26,27}$ a strong graphene-metal interaction is required to suppress oxidation. ${ }^{16}$ Thus, engineering the graphene-substrate interface is of crucial importance for many $2 \mathrm{D}$ material applications.

Here we study the influence of crystallographic orientation on the interaction and chemistry at the $2 \mathrm{D}-3 \mathrm{D}$ materials interface, specifically focusing on ambient oxidation at the buried graphene- $\mathrm{Cu}$ interface. Our model system is chemical vapor deposited (CVD) graphene on poly- and single- crystalline $\mathrm{Cu}$ substrates. There have already been a large number of reports on various aspects of the graphene $/ \mathrm{Cu}$ interaction and the related $\mathrm{Cu}$ oxidation/corrosion behavior. We therefore first summarize the salient points from these studies that we build on here, focusing particularly on room temperature conditions: for short time scales (minutes) graphene suppresses species reaching the $\mathrm{Cu}$ surface and thus protects $\mathrm{Cu}$ from corrosion in air and in corrosive liquids. $^{28-31}$ For longer time scales (hours to days) the presence of graphene can enhance corrosion due to galvanic corrosion. $^{23,29,32,33}$ For metals that interact strongly with graphene such that hybridization of the band structure occurs, the intercalation of species at the buried interface is suppressed. ${ }^{16}$ Whereas for comparatively weakly binding, such as graphene on $\mathrm{Cu}$, intercalation of species can more readily proceed. ${ }^{34,35}$ Isotope labeling studies have shown that under certain conditions the oxygen that forms the $\mathrm{Cu}$ oxide at the interface is from adsorbed water and not from the molecular oxygen in air, ${ }^{23}$ with similar results found on $\mathrm{Ru}(0001)$ at cryogenic temperatures, where dissociated water intercalates but not $\mathrm{O}_{2}$ or $\mathrm{H}_{2} \cdot{ }^{36}$ The graphene/ $\mathrm{Cu}$ interaction strength depends on the $\mathrm{Cu}$ crystal orientation as well as the epitaxial relationship, which leads to anisotropy in the $\mathrm{Cu}$

Received: June 1, 2020

Revised: August 25, 2020

Published: August 27, 2020 
oxidation rate at the graphene/ $\mathrm{Cu}$ interface for different $\mathrm{Cu}$ orientations. ${ }^{25,37-40}$ Graphene on $\mathrm{Cu}(111)$ and $\mathrm{Cu}(311)$ can form an epitaxial system where the interaction of graphene and $\mathrm{Cu}$ is comparatively strong, ${ }^{40-43}$ and the suppression of $\mathrm{Cu}$ surface oxidation seen for these systems has been attributed to this epitaxy. ${ }^{37,40,44}$ Interestingly, however, other $\mathrm{Cu}$ facets covered with noncommensurate graphene, such as $\mathrm{Cu}(124)$, have also been found to be relatively inert to oxidation. ${ }^{25}$

These previous studies on select graphene covered $\mathrm{Cu}$ facets motivate us here to systematically study ambient oxidation behavior for over 100 different (high and low index) $\mathrm{Cu}$ orientations. We employ complementary characterization by electron backscatter diffraction (EBSD), high spatial resolution (submicrometer spot size) X-ray scanning photoemission microscopy/microspectroscopy (SPEM, see Methods), Raman spectroscopy, and atomic force microscopy (AFM). Across the whole polar plot of surface orientations, we identify four general oxidation modes and rationalize the behavior of each with respect to the underlying mechanisms, and then further discuss their relevance and generality.

\section{RESULTS}

As a model substrate we use $1 \mathrm{~mm}$ thick, chemical mechanical polished (CMP), polycrystalline $\mathrm{Cu}$ (purity is $99.99 \%$ ) onto which without further pretreatment graphene islands were synthesized by CVD (see Methods). In addition, we use single crystal $\mathrm{Cu}$ (111), (011), and (001) substrates. Note the $\mathrm{Cu}(111)$ sample recrystallized into higher index surfaces during the CVD conditions used here (see the Supporting Information, SI). The CVD process results in a graphene nucleation density of approximately $30 \mathrm{~mm}^{-2}$, and using a growth time of $4 \mathrm{~h}$ leads to largely isolated graphene domains of roughly $250 \mu \mathrm{m}$ in lateral size. ${ }^{45}$ The graphene is predominantly monolayer, as has been shown previously. ${ }^{45}$ After the CVD process the lateral $\mathrm{Cu}$ grain dimensions of our model substrate are on the order of $1 \mathrm{~mm}$, as shown by the electron backscatter diffraction (EBSD) map in Figure 1(a).

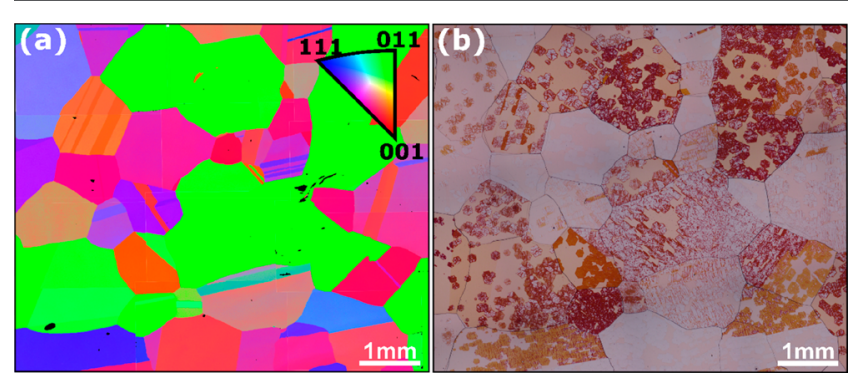

Figure 1. (a) Electron backscatter diffraction map (EBSD) of a polycrystalline $\mathrm{Cu}$ substrate after graphene CVD (see Methods). The sample was stored in air for 2 years. The inset shows the inverse pole figure (IPF) color code. (b) Corresponding optical microscope image. The observed color contrast reflects the degree of oxidation for different $\mathrm{Cu}$ facets underneath and between the graphene islands.

Highlighted by the inverse pole figure coloration, we find a range of different $\mathrm{Cu}$ surface orientations. The as-grown sample was stored in a class 10000 cleanroom for more than 2 years, with a controlled humidity level of $50 \%$ and a temperature of $21{ }^{\circ} \mathrm{C}$. Figure $1(\mathrm{~b})$ shows a corresponding optical microscope image. The observed contrast patterns highlight a very diverse, $\mathrm{Cu}$ facet dependent oxidation behavior underneath and in between the graphene islands.
It is well-known that a graphene coating can change the $\mathrm{Cu}$ oxidation behavior, and this effect is widely used to optically characterize graphene coverage and defects. ${ }^{37,46-49}$ The optical contrast and color can thereby be linked to the $\mathrm{Cu}$ oxide thickness, ranging from metallic white (unoxidized) to yellow, orange, and red with increasing thickness of the $\mathrm{Cu}$ oxide. ${ }^{50-53}$ We verify the correlation between optical contrast and degree of $\mathrm{Cu}$ oxidation via a combination of X-ray photoelectron spectroscopy (XPS) microscopy, Raman spectroscopy, and AFM. For XPS analysis, the sample was annealed at $100{ }^{\circ} \mathrm{C}$ in vacuum to remove surface contamination. In order to structure these large data sets, we employ image processing and color thresholding (see SI) on our optical microscopy data to extrapolate a quantitative parameter $\theta_{\text {ox }}$ that represents the extent of $\mathrm{Cu}$ oxidation based on areal coverage under graphene for a given $\mathrm{Cu}$ facet. We thereby only consider graphene covered areas, and for each crystallographic $\mathrm{Cu}$ orientation the $\theta_{\text {ox }}$-value was averaged over all pixels, with $\theta_{\mathrm{ox}}=\frac{\text { oxidized area under graphene }}{\text { graphene covered area }}$. The relative degree of oxidation of bare $\mathrm{Cu}$ areas, without graphene coverage, is characterized separately (see SI Figure S7).

Figure 2 shows $\theta_{\text {ox }}$ plotted onto the corresponding inverse pole figure (IPF), and it reveals four distinct modes of

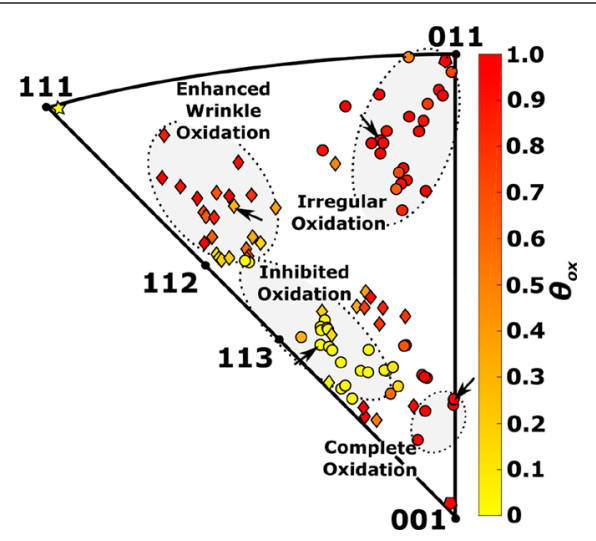

Figure 2. Extent of surface oxidation under graphene $\left(\theta_{\text {ox }}\right)$ for each $\mathrm{Cu}$ crystallographic orientation as computed by color thresholding and EBSD analysis. $\mathrm{Cu}$ facets with strong influence of wrinkles on oxidation are shown with rhombus shape. Note in the case of fully oxidized $\left(\theta_{\mathrm{ox}}=1\right)$ and for no oxidation $\left(\theta_{\mathrm{ox}}=0\right)$ no rhombuses are assigned as wrinkles cannot be distinguished. $\{001\}$ and $\{011\}$ single crystal $\mathrm{Cu}$ substrates are shown by pentagons. The $\{111\}$ orientation could not be verified here, and we display literature values ${ }^{40,44,54}$ with a star.

graphene/ $\mathrm{Cu}$ interface interaction. $\mathrm{Cu}$ orientations for which we observe the dominating influence of $\mathrm{Cu} /$ graphene corrugations/wrinkles on the oxidation are all marked with rhombuses. The data from $\{011\}$ and $\{001\}$ single crystal $\mathrm{Cu}$ substrates are shown by pentagons (see also SI Figure S6). We find that our $\mathrm{Cu}(111)$ single crystal recrystallizes into different higher index orientations under the conditions used, therefore we were not able to verify the oxidation behavior for this reference orientation. Instead, we include in Figure 2 literature values marked with a star for the $\{111\}$ orientation, which is reported not to cause interface oxidation even after extended air exposure. ${ }^{40,44,54} \mathrm{On} \mathrm{Cu}$ facets close to $\{111\}$ orientations, $\mathrm{Cu}$ oxidation occurs via a strong contribution from wrinkles. $\mathrm{On} \mathrm{Cu}$ facets close to $\{011\}$ orientations such wrinkle oxidation is not observed, and instead an irregular oxidation 

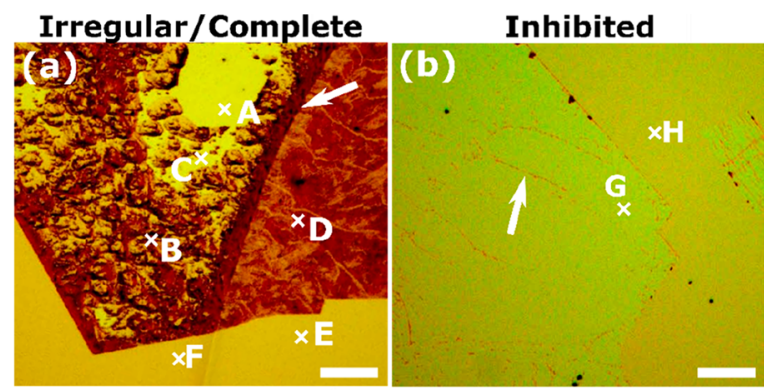

\section{Enhanced Wrinkle}
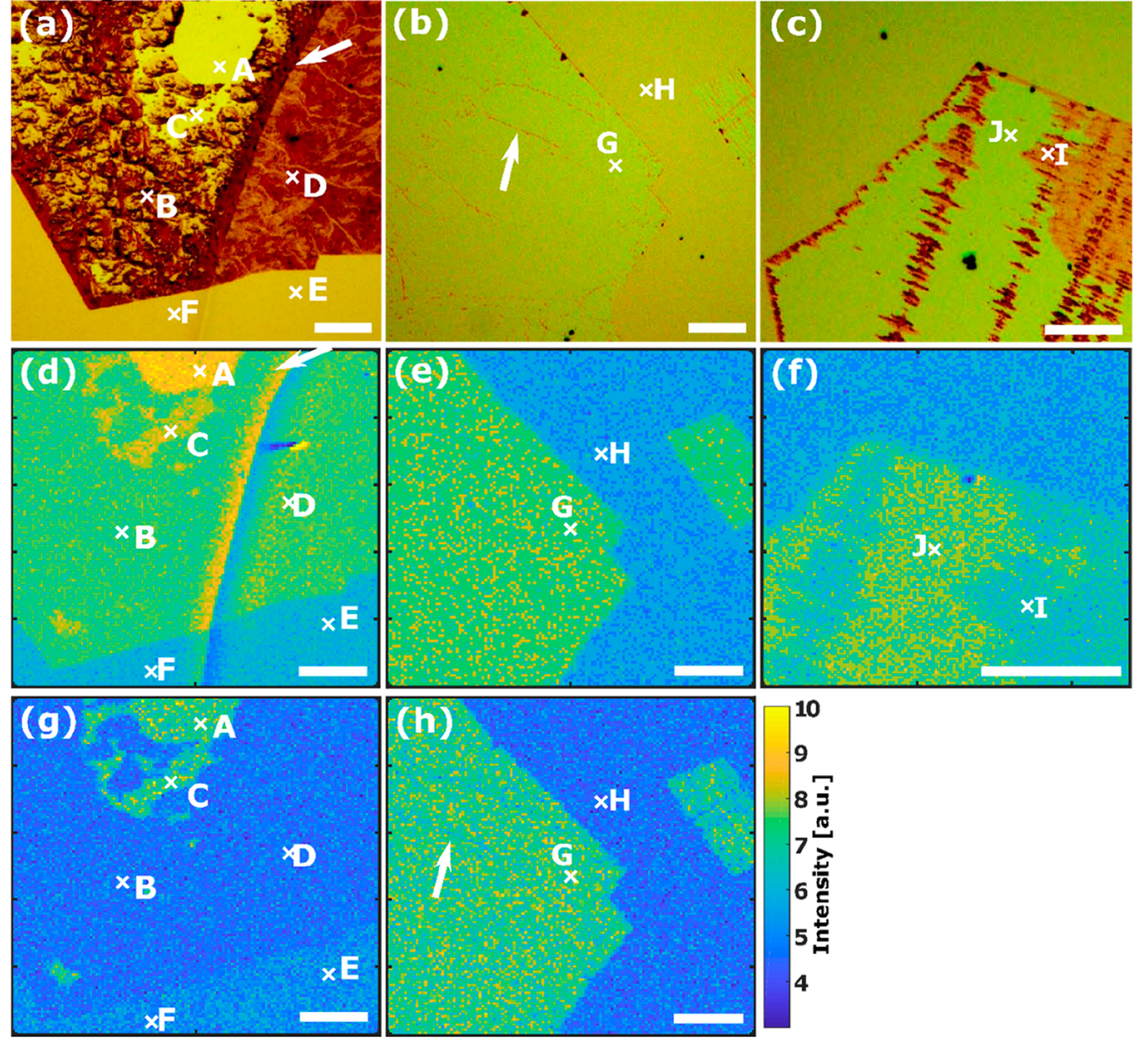

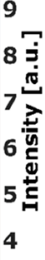

Figure 3. $(\mathrm{a}-\mathrm{c})$ Optical microscope images of the $\mathrm{Cu}$ substrate after CVD graphene synthesis and exposure to air for 2 years representative of the 4 regions indicated by arrows in Figure 2. (a) "Irregular Oxidation" on the left side of the image separated by a Cu grain boundary marked by an arrow. The right side represents a "complete oxidation" region. (b) Area representing "inhibited oxidation" only few thin wrinkles (one marked by arrow) show oxidation while the remaining graphene covered area is unoxidized. (c) Area representing "enhanced wrinkle oxidation". The letters A-J mark locations were Raman and XPS spectra were taken. (d-f) SPEM intensity maps of the C 1s region for the areas shown in (a-c). (g,h) SPEM chemical contrast maps of the Cu LMM peak for locations shown in (a,b), higher intensity (green) indicates unoxidized Cu and lower intensity (blue) the oxidized state. All scale bars are $20 \mu \mathrm{m}$.

pattern appears under the graphene. Complete oxidation (i.e., $\theta_{\text {ox }}$ approaching 1) is found on $\mathrm{Cu}$ facets close to $\{001\}$ orientations. For $\mathrm{Cu}$ facets close to $\{113\}$ orientations there is a region where we find values of $\theta_{\text {ox }}$ close to 0 , indicating that graphene completely inhibits $\mathrm{Cu}$ oxidation even after 2 years of air exposure. In the following we categorize these regions as "complete oxidation", "irregular oxidation", "inhibited oxidation", and "enhanced wrinkle oxidation", as mapped out and labeled in Figure 2. Data points representative of the oxidation behaviors of the four identified key interface characteristics are highlighted by black arrows in Figure 2. In the following we focus on detailed characterization of these representative points in order to develop an understanding of these distinct oxidation behaviors at the buried graphene/ $\mathrm{Cu}$ interface.

Figure 3 shows higher resolution optical microscopy images $(\mathrm{a}-\mathrm{c})$ combined with spatially resolved, synchrotron source SPEM maps $(\mathrm{d}-\mathrm{h})$. The optical microscopy data in Figure $3(\mathrm{a}-\mathrm{c})$ highlight that local phenomena influence the oxidation behavior, which we will describe and characterize in detail in the following. Figure 3(a) shows a graphene island that crosses a $\mathrm{Cu}$ grain boundary (highlighted by an arrow) and upon crossing of the $\mathrm{Cu}$ grain boundary the color and homogeneity of the copper oxide changes. We observe this phenomenon across the entire sample and graphene islands that cross a $\mathrm{Cu}$ grain boundary show an oxidation pattern that is dominated by the underlying $\mathrm{Cu}$ surface orientation (for details see Figures
S1 and S2) and apparently rather independent of the graphene flake and its relative orientation to the underlying $\mathrm{Cu}$. A brighter area in Figure 3(a), marked by the letter "A" which corresponds to a bilayer graphene region remained unoxidized [all other graphene covered regions in Figure 3 are monolayer graphene (see SI section 3)]. On the left side of the domain boundary in Figure 3(a) $\mathrm{Cu}$ shows an area of "irregular oxidation", whereas on the right side a region of "complete oxidation" is shown. Figure 3(b) shows bright contrast across all graphene covered regions corresponding to unoxidized $\mathrm{Cu}$ below the graphene layer except for narrow wrinkles with orange contrast. We label this as "inhibited oxidation". In strong contrast to the narrow wrinkles in Figure 3(b), Figure 3(c) shows parallel lines of dark red color where enhanced oxidation is found, and the remaining graphene covered region appears brighter in optical contrast and unoxidized. We label this region "enhanced wrinkle oxidation". In Figure 3(c) we observe that starting from a wrinkle the oxide preferentially grows anisotropically in the direction perpendicular to the wrinkle direction. Furthermore, the graphene island edges are also preferentially oxidized, and oxidation seems to proceed from the graphene island edge inward, in agreement previous reports. ${ }^{55,56}$

Conventional XPS with a spot size of several hundred $\mu \mathrm{m}$ is not suitable for resolving local oxidation behavior as observed here. Therefore, to unequivocally determine the oxidation state 
of $\mathrm{Cu}$ under the graphene layer with a resolution small enough to resolve local effects such as wrinkles and $\mathrm{Cu}$ grain boundaries, we here use SPEM (see Methods) that has submicrometer spatial resolution. Figure $3(d-f)$ shows the $C$ $1 \mathrm{~s}$ intensity maps acquired at $285.3 \mathrm{eV}$ binding energy corresponding to approximately the same locations as the optical images (Figure $3 a-c$ ). A clear contrast is visible in the $\mathrm{C}$ 1s maps between the graphene-covered and uncovered areas. When measuring the $\mathrm{C} 1 \mathrm{~s}$ signature on $\mathrm{Cu}$ and $\mathrm{Cu}_{2} \mathrm{O}$ there is also a change in background intensity, resulting in the contrast seen in Figure $3(\mathrm{~d}-\mathrm{f})$. The reason for this is, that the $\mathrm{Cu}$ signals have a higher intensity in the case of metallic $\mathrm{Cu}$ which results in a higher number of secondary electrons and thus a higher background level at the $\mathrm{C} 1$ s peak position. At the $\mathrm{Cu}$ grain boundary in Figure 3(d) the signal intensity is increased which is not related to oxidation, but to a topography artifact.

Since there is only a small binding energy difference in the $\mathrm{Cu} 2 \mathrm{p}_{3 / 2}$ core level peak for metallic $\mathrm{Cu}$ and $\mathrm{Cu}_{2} \mathrm{O}$, we focus here on the $\mathrm{Cu}$ LMM Auger-Meitner signature which is more sensitive to changes in the $\mathrm{Cu}$ oxidation state. ${ }^{34,58,59}$ Spatial mapping of the $\mathrm{Cu}$ LMM fingerprint region allows one to obtain chemical contrast maps which show the ratio of metallic to oxidized $\mathrm{Cu}$ (more details see Methods). They are shown in Figure $3(\mathrm{~g}, \mathrm{~h})$ and confirm that locations in white in the optical microscope image match to a $\mathrm{Cu}$ LMM chemical contrast intensity corresponding to unoxidized regions.

The letters "A-J" in Figure 3 mark points were XPS and Raman point spectra were taken to fully characterize these locations. Upon exposure to air $\mathrm{Cu}$ mainly forms $\mathrm{Cu}_{2} \mathrm{O}, \mathrm{CuO}$, and $\mathrm{Cu}(\mathrm{OH})_{2}$. Note that prior to the XPS measurement, the sample was annealed at $100{ }^{\circ} \mathrm{C}$ in vacuum to remove surface contamination but which could also begin to reduce any $\mathrm{CuO}$ present to $\mathrm{Cu}_{2} \mathrm{O},{ }^{60}$ given its instability in vacuum. ${ }^{61}$ Figure 4 shows the Cu LMM spectra of locations "A-J" and the peak positions of the most intense peak corresponding to $\mathrm{Cu}_{2} \mathrm{O}$, $\mathrm{CuO}$, and $\mathrm{Cu}(\mathrm{OH})_{2}$, whose kinetic energies are shifted with respect to the metallic peak by $-1.04,-1.62$, and $-2.36 \mathrm{eV},{ }^{57}$ respectively. The $\mathrm{Cu}$ LMM signature is very complex, and in Figure 4 we only mark the location of the most intense peak for the species indicated (for further details see Figure S10). In line with the optical microscopy images, points "A", "C", "G", and "J" show a Cu LMM spectra corresponding to unoxidized $\mathrm{Cu}$, whereas the remaining spectra show Cu LMM spectra corresponding to oxidized $\mathrm{Cu}$ (peak fitting confirms this; see SI section 2). Cu LMM peak fitting (see SI Figure S10) reveals that the presence of a graphene overlayer alters the oxide composition. Graphene covered and oxidized regions " $\mathrm{B}$ ", " $\mathrm{D}$ ", and " $\mathrm{I}$ " consist of only $\mathrm{Cu}_{2} \mathrm{O}$, whereas locations "E", "F", and " $\mathrm{H}$ " that correspond to graphene uncovered regions are composed of a mixture of $\mathrm{Cu}_{2} \mathrm{O}$ and $\mathrm{CuO}$.

Location " $\mathrm{A}$ " refers to a bilayer region and Figure 4 shows that " $A$ " is unoxidized although the remaining $\mathrm{Cu}$ areas beneath monolayer regions of this graphene domain are oxidized. This highlights that bilayer graphene shows a very different interface oxidation behavior compared to monolayer graphene.

Figure 5 shows Raman mapping data corresponding to the same sample regions as in Figure 3, performed to resolve the effect of $\mathrm{Cu}$ orientation and oxidation on the graphene doping concentration and strain. We present the Raman data as scatter plots of $\mathrm{G}$ peak wavenumber $\left(\omega_{\mathrm{G}}\right)$ vs $2 \mathrm{D}$ peak wavenumber $\left(\omega_{2 \mathrm{D}}\right)$ for the four key regions (Figure 2), to highlight the different local strain $(\varepsilon)$ and doping $(|n|)$ concentra-

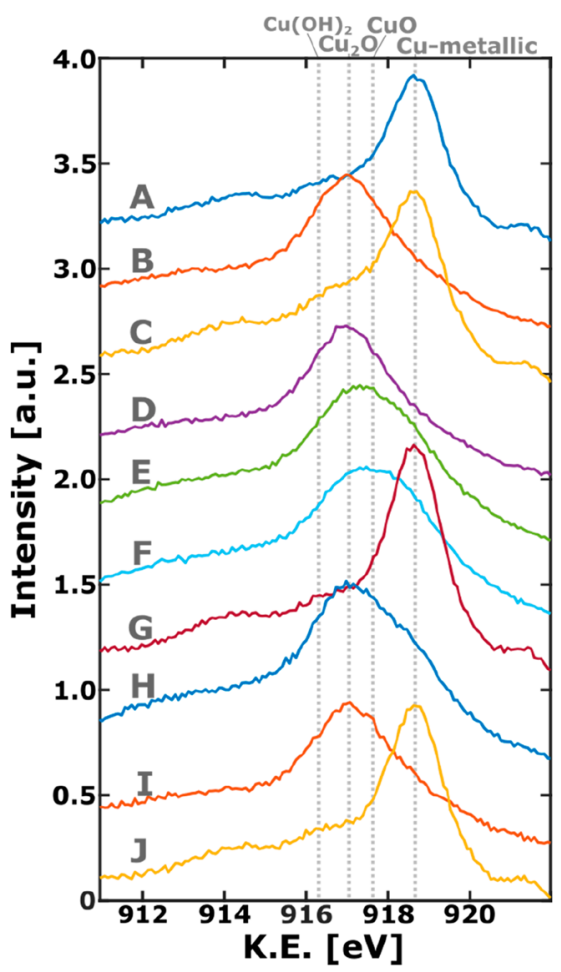

Figure 4. XPS Cu LMM Auger-Meitner spectra of locations A-J. As a guide to the eye, the gray dotted lines mark the peak positions relating to the most intense $\mathrm{Cu} \mathrm{LMM}$ peaks for metallic $\mathrm{Cu}, \mathrm{CuO}, \mathrm{Cu}_{2} \mathrm{O}$, and $\mathrm{Cu}(\mathrm{OH})_{2}$ (for peak fitting see Figure S10). ${ }^{57}$

tions. $^{13,62-64}$ The color bar indicates the full width halfmaximum (fwhm) of the 2D peak, which is an indication of local strain homogeneity. ${ }^{64}$ There is a clear trend in how the strain in the graphene relates to the $\mathrm{Cu}$ oxidation state irrespective of the $\mathrm{Cu}$ orientation. Oxidized $\mathrm{Cu}$ regions result in tensile strain $(\varepsilon>0)$ in the graphene layer (Figure 5(a, b, and some regions in $\mathrm{d})$ ), whereas unoxidized regions are under compressive strain $(\varepsilon<0)$ ((Figure 5(c and parts of $d))$. Irrespective of the $\mathrm{Cu}$ grain, we observe a very widespread in graphene strain that ranges approximately from $0 \lesssim \varepsilon \lesssim 0.8 \%$ on oxidized areas and from $-0.8 \lesssim \varepsilon \lesssim 0 \%$ on unoxidized areas. The graphene doping concentration also correlates with the underlying $\mathrm{Cu}$ oxidation state: in the case of "inhibited oxidation" we find the overall lowest doping concentration of approximately $|n| \cong \sim 0-0.5 \times 10^{13} \mathrm{~cm}^{-2}$. For "complete oxidation" $|n|$ appears to converge to a value of approximately $\mid$ $n \mid \cong 1 \times 10^{13} \mathrm{~cm}^{-2}$, and for "irregular oxidation" $|n|$ is inbetween the oxidized and unoxidized case and shows a larger spread from $|n| \cong \sim 0-1 \times 10^{13} \mathrm{~cm}^{-2}$. This is in line with the $\mathrm{C}$ 1s spectra provided in Figure S9, where a change in the level of charge transfer between the $\mathrm{Cu}$ and graphene results in a binding energy shifts of the $\mathrm{C} 1 \mathrm{~s}$ core level. Here, a shift toward higher binding energies of approximately $0.15-0.25 \mathrm{eV}$ suggesting n-type doping for locations " $\mathrm{A}$ ", "B", "C", “ $\mathrm{D}$ ”, and "I" is observed but no binding energy shift is observed for position "G" and only a small shift of approximately $0.05-0.1$ $\mathrm{eV}$ is seen for location "J".

We further note that the $\mathrm{Cu}$ crystallographic dependent oxidation behavior described above is not limited to graphene islands, but the same $\mathrm{Cu}$ grain dependent oxidation behavior is observed for samples with full graphene coverage (see SI Figure S18). Furthermore, the results presented here are not 

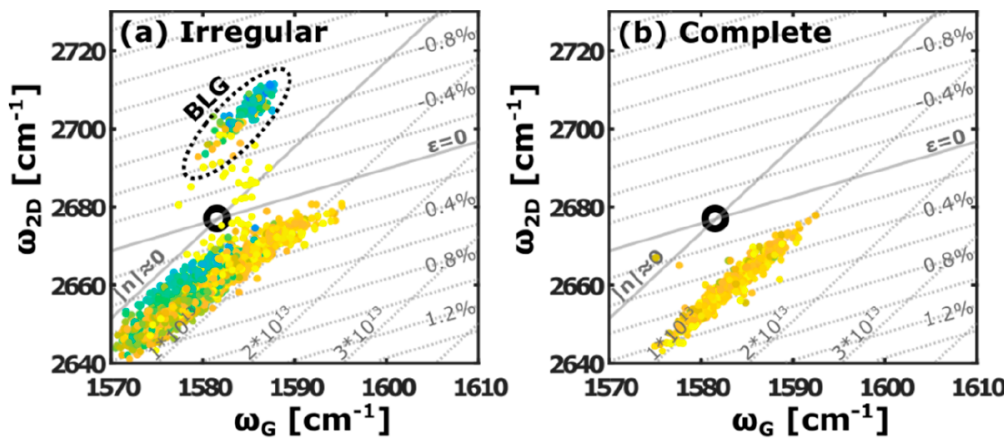

60
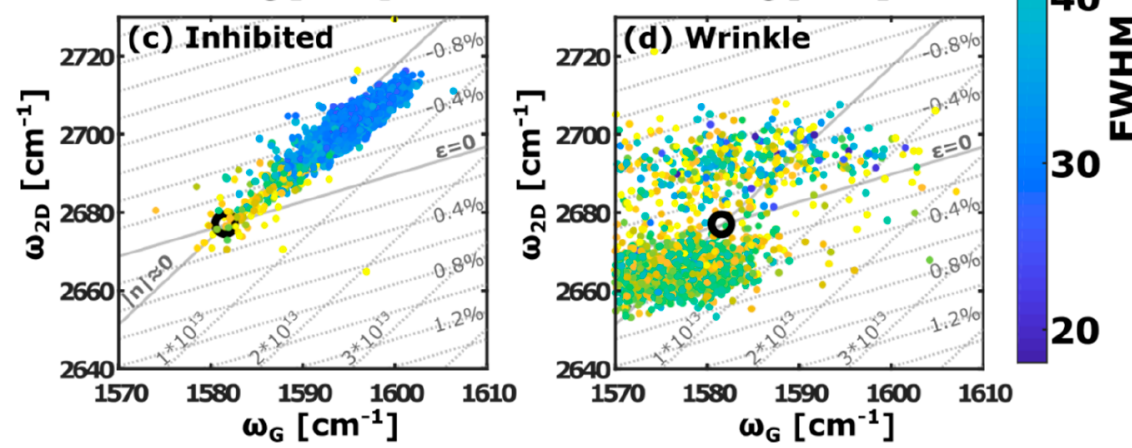

Figure 5. Scatter plot of $\mathrm{G}$ peak position $\left(\omega_{\mathrm{G}}\right)$ and $2 \mathrm{D}$ peak position $\left(\omega_{2 \mathrm{D}}\right)$ as well as the full width half-maximum (fwhm) of the $2 \mathrm{D}$ peak indicated by color. $\varepsilon$ refers to strain in $\%$ and $|n|$ to the carrier concentration in $\mathrm{cm}^{-2}$. (a) Refers to the data acquired at the region "irregular oxidation", the data points labeled BLG correspond to the bilayer graphene region, (b) to the region "complete oxidation", (c) to the region "inhibited oxidation", and (d) to the region "enhanced wrinkle oxidation".

limited to CMP polished $\mathrm{Cu}$ substrates but equally apply to cold rolled thin $(25 \mu \mathrm{m}) \mathrm{Cu}$ foils that are substantially rougher $\left(R_{\mathrm{a}} \approx 300 \mathrm{~nm}\right) .^{45}$ SI Figure $\mathrm{S} 19$ shows that $\mathrm{Cu}$ grain dependent oxidation behavior following the 4 different oxidation categories identified in Figure 2 is also observed on these rough cold rolled $\mathrm{Cu}$ foils on which graphene was grown and which were exposed to air.

Whereas our study primarily focuses on the oxidation at the graphene $/ \mathrm{Cu}$ interface under ambient conditions, we also performed a wet oxidation treatment to investigate the $\mathrm{Cu}$ orientation dependence under such different, comparatively harsher conditions. ${ }^{23,65}$ In order to use the same sample, the $\mathrm{Cu}$ interface oxidation was reduced by hydrogen annealing. ${ }^{34}$ Annealing for $3 \mathrm{~h}$ at $250{ }^{\circ} \mathrm{C}$ and $5 \mathrm{mbar}_{2}$ reduces the oxide at the graphene $\mathrm{Cu}$ interface (see SI section 5). ${ }^{34,35}$ After reduction, we immerse the $\mathrm{Cu} /$ graphene sample in deionized water at $50{ }^{\circ} \mathrm{C}$ for 3 days, which causes wet-oxidation of the graphene $/ \mathrm{Cu}$ interface. ${ }^{4}$ In contrast to the above-described oxidation in ambient conditions, the microscope color contrast shows that wet oxidation at these conditions leads to uniform oxidation across all $\mathrm{Cu}$ crystallographic orientations (see SI section 5). Compared to oxidation in air, interface oxidation in water is significantly accelerated. ${ }^{23,66,67}$ Furthermore, Raman spectroscopy analysis shows very low residual strain after water oxidation compared to air oxidation and in the case of water oxidation also graphene bilayer regions can be intercalated and oxidized.

\section{DISCUSSION}

The results herein show that for the graphene- $\mathrm{Cu}$ interface, there are several effects that influence the interface oxidation behavior, and these effects are strongly linked to the $\mathrm{Cu}$ surface orientation. The characteristic oxidation patterns observed can be associated with regions in the IPF plot rather than discrete
$\mathrm{Cu}$ orientations (Figure 2). On the basis of this we can exclude epitaxial effects between graphene and the underlying $\mathrm{Cu}$ as a major influence on the observed oxidation behavior. Furthermore, Figure 3(a) (see also Figure S1) shows that if a graphene island crosses a $\mathrm{Cu}$ grain, then the oxidation pattern drastically changes at the $\mathrm{Cu}$ grain boundary to resemble that of the other islands on the new $\mathrm{Cu}$ grain, which indicates that the underlying $\mathrm{Cu}$ is the dominant factor in oxidation rather than a particular graphene orientation relative to the $\mathrm{Cu}$. The dark red color in the optical microscope images indicates that some areas under the graphene develop a thicker $\mathrm{Cu}$-oxide compared to the bare $\mathrm{Cu}$ surface, hinting at a galvanic corrosion mechanism. ${ }^{23,29,32,33}$ Galvanic corrosion is driven by a work function difference between graphene and $\mathrm{Cu}$. The work function of $\mathrm{Cu}$ is highly dependent on the $\mathrm{Cu}$ surface. ${ }^{68-71}$ In a simple model, the work function of a surface is directly correlated to the step density where the steps add additional dipole moments to the edge atoms (see also the "Smoluchowski-effect" $\left.{ }^{72}\right)$, i.e., the work function decreases with increasing step density $\{111\}(4.7 \mathrm{eV})>\{100\}(4.5 \mathrm{eV})>$ $\{211\}(4.5 \mathrm{eV})>\{123\}(4.4 \mathrm{eV})>\{110\}(4.3 \mathrm{eV})>\{310\}(4.3$ $\mathrm{eV}) .^{73}$ The work function of (undoped) graphene is around 4.5 $e V .^{74-76}$ Hence, if a surface, for example the $\{111\},\{100\}$, and $\{211\}$ orientations, have a work function higher than or equal to graphene, then no galvanic corrosion would be expected in this simplified model. In contrast, if the work function of the $\mathrm{Cu}$ surface is lower than the work function of graphene, e.g., vicinals of the $\{110\}$ orientation, then galvanic corrosion effects are expected. Indeed, the overall picture in Figure 2 resembles some of these trends, i.e., vicinals of the $\{111\}$ orientation with the highest work function mostly show oxidation along the wrinkles but no oxidation in unwrinkled areas (see Figure $3 c, f$ ) and the inhibited oxidation region corresponds to an area with work function of approximately 
$4.5 \mathrm{eV}$. Vicinals of the $\{110\}$ orientation have relatively lower work functions, and we indeed see increased oxidation including the complete oxidation region, consistent with galvanic corrosion. Further evidence for this argument is that the acquired Raman spectra on areas corresponding to the "inhibited oxidation" region of the IPF do not show doping effects (see Figure 5(c)), indicating negligible difference between the $\mathrm{Cu}$ and graphene work functions. This is also the case after water oxidation (see Figure S17(b)). We note that the graphene covered surfaces shown in AFM maps of Figure $S 13$ have a surface roughness $\left(R_{\mathrm{a}}\right)$ ranging from approximately 5 to $20 \mathrm{~nm}$. The $\mathrm{Cu}$ work function decreases with increasing surface roughness and therefore the actual surface work function will be a convolution of the surface roughness and facet specific work function. ${ }^{77}$ Also note that the electron beam penetration depth used for EBSD here is on the order of 50-100 nm. ${ }^{78}$ Therefore, the graphene layer may locally be in contact with a range of other surface facets due to the surface roughness and surface reconstructions that are not captured by the EBSD measurement. ${ }^{79}$ Nevertheless, there is a strong correlation of the interface oxidation behavior to the EBSD measured surface orientation despite the graphene layer being in contact with a rough surface. This not only holds for the flat samples used here, but also for comparatively rough $\left(R_{\mathrm{a}}\right.$ $\approx 300 \mathrm{~nm})^{45} \mathrm{Cu}$ foils (see Figure S18). Further evidence for the strong contribution of galvanic corrosion are comparative studies of insulating hexagonal boron nitride (h-BN) monolayers on $\mathrm{Cu}$, which are shown to be better long-term corrosion barriers than graphene, as insulating h-BN layer cannot drive galvanic effects. ${ }^{80-82}$

Assuming a defect free graphene layer is impermeable to gas molecules, ${ }^{83,84}$ for oxidation to occur oxygen species must intercalate beneath the graphene layer to react with the underlying $\mathrm{Cu}$ surface. We do not detect a Raman $\mathrm{D}$ peak away from the edges of the graphene domains on any $\mathrm{Cu}$ orientation (see Figure S11), however defect densities $\left(n_{\mathrm{D}}\right)$ on the order of less than $n_{\mathrm{D}} \approx 5 \mu \mathrm{m}^{-2}$ on $\mathrm{Cu}$ substrates are very challenging to resolve with Raman. ${ }^{85}$ Therefore, for $\mathrm{Cu}$ oxidation to occur under graphene, oxygen species need to diffuse through the graphene layer via defects or intercalate via the edges. For oxidation to proceed, the diffusion pathway must remain active and not be self-passivating upon oxidation. Additional AFM images in the SI (see Figure S13) show that there is no obvious correlation between surface roughness and the oxidation behavior with the exception of wrinkles (Figure $\mathrm{S} 13(\mathrm{f}, \mathrm{g})$ ). The areas under the graphene wrinkles are oxidized, which indicates that the $\mathrm{Cu}$-graphene interaction is weakened in these areas and oxygen species can more easily penetrate the interface here. For the $\mathrm{Cu}$ grains classified as "enhanced wrinkle oxidation" (Figure S13(f,g)) we also observe a regular surface corrugation pattern on unoxidized areas, and these corrugations are perpendicular to wrinkles. The surface corrugations correlate to the anisotropic oxide growth rate that is observed in direction of the corrugation and may be explained by an accelerated oxide species diffusion rate along the corrugation compared to oxide diffusion across the corrugation. These surface corrugation have previously been described as $\mathrm{Cu}$ step bunches. ${ }^{86}$ The existence of such $\mathrm{Cu}$ step bunches, wrinkle formation and variations in strain are commonly rationalized via a thermal expansion coefficient mismatch between graphene and $\mathrm{Cu}$. The thermal expansion coefficient mismatch causes the graphene film to be under compressive stress and the $\mathrm{Cu}$ surface layer to be under tensile stress. $^{43,86-90}$ The $\mathrm{Cu}$ surface can be considered as highly mobile or "pre-molten" at the CVD conditions used, however such premelting behavior is also dependent on the $\mathrm{Cu}$ crystallographic orientation. ${ }^{91}$ Upon cooling the tensile stress in the $\mathrm{Cu}$ surface layer is relaxed by the formation of step bunches. ${ }^{86}$ The compressive strain in graphene is relaxed by out of plane wrinkle formation, which again is dependent on the $\mathrm{Cu}$ crystallographic interaction strength of the graphene$\mathrm{Cu}$ interface. ${ }^{43,86-90}$ This is consistent with our measurements in Figure 5(d) (see also Figures S11 and S12), where we observe reduced strain along a graphene wrinkle. Upon intercalation and interface oxidation there is a volume expansion due to $\mathrm{Cu}$ oxidation and thus the compressive strain in graphene is released and graphene is under tensile strain (see Figure 5). Previous reports describe how such $\mathrm{Cu}$ corrugations can relax in graphene wrinkles which occur perpendicular to the $\mathrm{Cu}$ surface corrugation. ${ }^{86}$ Corrugations perpendicular to wrinkles are consistent with our observation in Figure S13. Previous reports also observed oxidation along wrinkles for orientations close to $\mathrm{Cu}\{111\}$ and $\{001\}$ but not on surfaces closest to $\{011\}$, which is in line with our findings. ${ }^{92}$ Indeed, the $\mathrm{Cu}$ thermal expansion coefficient is dependent on the $\mathrm{Cu}$ crystal orientation but these differences in thermal expansion coefficient are relatively small. ${ }^{93}$

Figure S13 shows how different graphene covered $\mathrm{Cu}$ orientations reconstruct and as a result the surface roughness becomes markedly different. Differences in surface roughness can have notable effects on the hydrophobicity of a surface and thereby drastically change the oxidation rates. ${ }^{94-98}$ It is wellknown that hydrophobic $\mathrm{Cu}$ surfaces exhibit increased corrosion protection when exposed to atmospheric conditions. ${ }^{99}$ Furthermore, water diffusion at the graphene substrate interface was shown to be significantly increased by increasing the hydrophilicity of the substrate. ${ }^{100}$ However, the fact that we observe similar surface roughness for the "inhibited oxidation" and "complete oxidation" case hints that the difference is not pronounced when $\mathrm{Cu}$ is stored in air. However, prolonged immersion in water at $50{ }^{\circ} \mathrm{C}$ eventually leads to oxidation on all surface orientations (see SI section 5), in line with previous reports that have shown accelerated oxidation rates in water. ${ }^{23,66,67}$ By isotope labeling Luo et al. ${ }^{23}$ have shown that water, and not oxygen species from air, is the main contributor to the interface oxide. Our data are consistent with this. An acceleration of the oxidation rate can be obtained by supplying water vapor or by immersion in water.

While the above has focused on graphene covered $\mathrm{Cu}$, it is also known that the oxidation rate varies with surface orientation for bare $\mathrm{Cu} .^{101-106}$ The oxidation rate of a bare $\mathrm{Cu}$ surface correlates with the surface step density during the initial phase of oxidation and therefore an orientation dependent oxide formation rate is expected. ${ }^{101-104}$ However, the subsequent oxide growth process is complex and depends on various factors that cannot be solely explained by the surface step density. ${ }^{105,106}$ Figure 1(b) shows an orientation dependent color contrast also for bare $\mathrm{Cu}$ regions. The relative orientation dependent oxide rate is further quantified in Figure S7 (b) and mapped in an IPF plot in similar fashion to Figure 2. Comparing Figures 2 and S7(b), a strong correlation between the oxidation behavior of graphene covered and bare $\mathrm{Cu}$ regions is observed. The orientations that are marked as inhibited oxidation under graphene in Figure 2 also show relatively low oxidation for bare $\mathrm{Cu}$ regions. Orientations with irregular and complete oxidation under graphene also show the 
highest degree of oxidation for bare $\mathrm{Cu}$ regions (see Figure S7(b)). A notable difference in oxidation extent is the "enhanced wrinkle" orientations, where without the presence of graphene a relatively low degree of oxidation is observed. This highlights the argument above, that wrinkles enable oxygen species to diffuse and cause oxidation locally. Whereas graphene covered and bare $\mathrm{Cu}$ oxidation mostly show a similar trend when comparing patterns across the IPF, the oxide thickness and oxide composition are distinctly different. Our XPS data show that a graphene layer changes the $\mathrm{Cu}$ oxide composition and underneath graphene only $\mathrm{Cu}_{2} \mathrm{O}$ is observed, whereas bare $\mathrm{Cu}$ regions are composed of a mixture of $\mathrm{CuO}$ and $\mathrm{Cu}_{2} \mathrm{O}$ (see Figures S9 and S10). ${ }^{55}$ Previous reports have shown that when $\mathrm{Cu}$ is exposed to air, $\mathrm{CuO}$ is only observed at the surface in direct contact with the atmosphere and a thicker $\mathrm{Cu}_{2} \mathrm{O}$ layer is found underneath the $\mathrm{CuO}$ layer. ${ }^{107}$ Thus, for graphene covered oxide regions the graphene layer is protecting the $\mathrm{Cu}_{2} \mathrm{O}$ layer from contact with the atmosphere and therefore prevents the $\mathrm{Cu}_{2} \mathrm{O}$ layer from further oxidizing to $\mathrm{CuO}$. We here focus on monolayer graphene films, but note that for areas covered with bilayer graphene, no $\mathrm{Cu}$ oxidation is observed at ambient conditions (see Figure 3a,d,g). Mismatched defects between the layers in bilayer graphene hinder diffusion of oxygen species in the vertical direction compared to monolayer graphene. ${ }^{108}$ Furthermore, we do not observe wrinkles in the bilayer region (see Figure S13c), which when present provide additional pathways for oxygen species to access the $\mathrm{Cu}$ surface. This may explain why we do not observe oxidation under bilayer graphene (see Figure $3 \mathrm{a}, \mathrm{d}, \mathrm{g}$ ), even on a $\mathrm{Cu}$ orientation where otherwise higher oxide coverages are observed. However, in more corrosive oxidation environments, e.g., by water immersion ( $50{ }^{\circ} \mathrm{C}$ for 3 days) even bilayer regions become oxidized (see Figure $\mathrm{S} 15(*)$ ). This suggests that bilayer graphene does not offer a different corrosion protection mechanism beyond fewer penetration pathways for oxygen species, as eventually the oxidation front will intercalate from the graphene island edges inward irrespective of defect density.

\section{CONCLUSIONS}

We have synthesized graphene islands on flat polycrystalline $\mathrm{Cu}$ substrates with a range of different $\mathrm{Cu}$ orientations. After exposure to ambient conditions for 2 years, $\mathrm{Cu}$ grain orientation dependent oxidation was observed that can be classified as complete-, irregular-, inhibited-, and enhanced wrinkle-interface oxidation. The characteristic oxidation patterns observed are associated with regions in the IPF plot rather than discrete $\mathrm{Cu}$ orientations (see Figure 2). Our results clearly demonstrate that under ambient conditions, the $\mathrm{Cu}$ orientation is the dominant factor in determining the oxidation behavior under graphene, as our experimental design accounts for factors such as surface roughness, different growth conditions, and different graphene quality on each domain, allowing these to be excluded. We expect the observed classification to be relevant to different oxidizing environments, such as saturated water vapor now widely used for graphene transfer. Indeed, our generalized groupings and mapping onto the polar plot of $\mathrm{Cu}$ surface orientations consistently consolidates a large body of previous literature on select individual $\mathrm{Cu}$ orientations, all under slightly different conditions. Our example of immersion in water, however, shows that for very corrosive conditions ultimately all $\mathrm{Cu}$ orientations can be oxidized underneath the graphene (mono- or bilayer), i.e., the described $\mathrm{Cu}$ orientation dependent effects should be understood with respect to given exposure conditions. Recent reports have demonstrated the production of high and low index $\mathrm{Cu}$ foils with desired orientation, ${ }^{109}$ which enables the findings of this paper to be translated beyond individual grains. We expect our study to facilitate future optimization of process technology tailored to diverse emerging application needs for graphene and other 2D materials that face analogous challenges, ranging from complete and uniform intercalation and interface oxidation as required for example for optimized $2 \mathrm{D}$ layer transfer to complete oxidation protection by an atomic monolayer for instance for plasmonics.

\section{METHODS}

Chemical mechanical polished (CMP), polycrystalline $\mathrm{Cu}$ metallic substrate (dimensions $1 \times 10 \times 10 \mathrm{~mm}^{3}$ ) as well as single crystals with orientation (111), (011), and (001) were used as graphene growth substrate. According to distributor specifications (PiKem Limited) the Cu purity is $99.99 \%$ and the surface roughness is $R_{\mathrm{a}}<3$ $\mathrm{nm}$.

CVD was performed in a commercial Aixtron Black Magic 4 in. system. The $\mathrm{Cu}$ substrate was loaded into the CVD system without further surface treatment. CVD synthesis was performed by heating in Ar atmosphere at $100{ }^{\circ} \mathrm{C} / \mathrm{min}$ to $1065^{\circ} \mathrm{C}$. The sample was annealed for $30 \mathrm{~min}$ which leads to $\mathrm{Cu}$ grain growth for the polycrystalline substrates, followed by carbon precursor injection (gas flow rates Ar: $\mathrm{H}_{2}: \mathrm{CH}_{4}(0.1 \%$ diluted in Ar) $=250 \mathrm{sccm}: 26 \mathrm{sccm}: 12 \mathrm{sccm})$ for a growth time of $4 \mathrm{~h}$ after which the heaters were switched off and the chamber was cooled to room temperature in an $\mathrm{Ar}$ atmosphere. ${ }^{45}$ During all process steps, the chamber pressure was $50 \mathrm{mbar}$.

After synthesis the $\mathrm{Cu}$ substrate was stored in a class 10000 cleanroom atmosphere for 2 years. The temperature of the cleanroom was regulated to $21{ }^{\circ} \mathrm{C}$, and the air humidity was regulated to $50 \%$.

The model system employed here allows us to rule out a series of uncertainties. Unlike the commonly used cold rolled $\mathrm{Cu}$ foils for graphene synthesis, we used polished $\mathrm{Cu}$ substrate to rule out surface roughness induced effects on oxidation. Analyzing graphene islands which have previously been established to be predominantly single graphene domains, ${ }^{45}$ we can rule out the effect of graphene domain boundary induced defects as pathways for intercalation of oxygen species, ${ }^{46,110}$ or sites for enhanced dissociation of intercalating species. ${ }^{36}$ Furthermore, a $\mathrm{Cu}$ sample which is only partially covered with graphene islands allows direct comparison between the oxidation rate of the uncovered and graphene-covered areas. Using a single polycrystalline substrate rather than a series of single crystalline substrates ensures that the growth conditions were equal on all $\mathrm{Cu}$ grains as gas flux and temperature dependence can be assumed to be negligible over the $1 \mathrm{~cm}^{2}$ sample area in a 4 in. cold wall showerhead CVD reactor. ${ }^{111}$ At the growth conditions used here CVD graphene defect densities are on a similar order for all $\mathrm{Cu}$ grains ${ }^{112}$ and further we can observe graphene single domain islands that cross $\mathrm{Cu}$ grain boundaries to clearly show the effect of underlying $\mathrm{Cu}$ orientation.

Raman analysis was performed in a Renishaw inVia Raman microscope with a $532 \mathrm{~nm}$ laser with $100 \times$ objective and a $1800 \mathrm{l} /$ $\mathrm{mm}$ grating. Scanning electron microscopy (SEM) analysis was performed using a Carl Zeiss SIGMA VP at an acceleration voltage of $2 \mathrm{kV}$.

The EBSD was conducted on a FEI Nova NanoSEM scanning electron microscope with an acceleration voltage of $20 \mathrm{kV}$. The sample was tilted at $70^{\circ}$ toward the EBSD detector, which was approximately $20 \mathrm{~mm}$ from the surface of the sample. The contrast and the background subtraction of the electron backscatter diffraction patterns were optimized to maximize signal strength prior to each mapping measurement. Multiple maps were taken and later stitched together to form the image maps used in this work.

Scanning X-ray Photoelectron Microscopy/microspectroscopy (SPEM) measurements were carried out at the Escamicroscopy 
beamline of the Elettra synchrotron facility (Trieste, Italy). ${ }^{113}$ Samples were first annealed in vacuum to $\sim 100{ }^{\circ} \mathrm{C}$ to remove residual surface contamination that otherwise obscures the signal from the $\mathrm{Cu} /$ graphene interface, with the temperature chosen to avoid significant changes to the $\mathrm{Cu}$ oxidation state ${ }^{60}$-although the instability of $\mathrm{CuO}$ may lead to its partial reduction to $\mathrm{Cu}_{2} \mathrm{O}$ particularly under $\mathrm{X}$-ray irradiation. ${ }^{61}$ The $\mathrm{X}$-ray beam was focused to a 180-200 nm spot by a Fresnel zone plate based optics.

For both imaging and submicron spectroscopy, a SPECSPHOIBOS 100 hemispherical electron energy analyzer with an inhouse customized 48 channel delay line detector was used. ${ }^{114} \mathrm{~A}$ photon energy of $1074 \mathrm{eV}$ was employed. The SPEM can mainly work in two modes: (i) microspectroscopy mode, i.e., the typical energy scanning mode employed in any standard XPS system, using a 180$200 \mathrm{~nm}$ X-ray spot size, and (ii) imaging mode can map the photoelectrons emitted within a selected kinetic energy window by scanning the specimen with respect to the focused X-ray beam. In the imaging mode, each channel of the detector corresponds to slightly different energy, resulting in a 48 data point spectrum at each pixel. All binding energies are referenced to the $\mathrm{Cu} 2 \mathrm{p}$ peak energy which was set to be $932.6 \mathrm{eV}$. This approach is feasible on our sample because there is only a modest change between the metallic $\mathrm{Cu}$ and the $\mathrm{Cu}_{2} \mathrm{O}$ peak position and only small amounts of $\mathrm{CuO}$ are present. ${ }^{59}$ To acquire the map of the $\mathrm{C} 1$ s peak in Figure $3(\mathrm{~d}-\mathrm{f})$ the energy window of the analyzer was centered at a binding energy of $285.3 \mathrm{eV}$ and for the $\mathrm{Cu} \mathrm{LMM}$ it was set to the kinetic energy of $917.0 \mathrm{eV}$. To obtain the Cu LMM chemical contrast maps shown in Figure $3(\mathrm{~g}, \mathrm{~h})$ the integral ratio of the spectral regions containing mainly metallic (918.1-919.9 eV) and oxidized (915.8-918.1 eV) contributions was calculated and plotted for each pixel.

\section{ASSOCIATED CONTENT}

\section{(s) Supporting Information}

The Supporting Information is available free of charge at https://pubs.acs.org/doi/10.1021/acs.chemmater.0c02296.

Additional optical microscope and EBSD data; details on approach for color thresholding; additional XPS, Raman, and AFM data; and details and characterization of water oxidized samples and oxidation characteristics of additional samples (PDF)

\section{AUTHOR INFORMATION}

\section{Corresponding Authors}

Philipp Braeuninger-Weimer - Department of Engineering, University of Cambridge, Cambridge CB3 OFA, United Kingdom; 이이. orcid.org/0000-0001-8677-1647; Email: philipp.braeuninger@gmail.com

Stephan Hofmann - Department of Engineering, University of Cambridge, Cambridge CB3 OFA, United Kingdom; (1) orcid.org/0000-0001-6375-1459; Email: sh315@ cam.ac.uk

\section{Authors}

Oliver J. Burton - Department of Engineering, University of Cambridge, Cambridge CB3 OFA, United Kingdom

Patrick Zeller - Elettra-Sincrotrone Trieste S.C.p.A., 34149 Trieste, Italy

Matteo Amati - Elettra-Sincrotrone Trieste S.C.p.A., 34149 Trieste, Italy

Luca Gregoratti - Elettra-Sincrotrone Trieste S.C.p.A., 34149 Trieste, Italy

Robert S. Weatherup - Department of Materials, University of

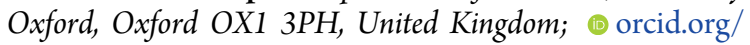
0000-0002-3993-9045

Complete contact information is available at: https://pubs.acs.org/10.1021/acs.chemmater.0c02296

\section{Notes}

The authors declare no competing financial interest.

\section{ACKNOWLEDGMENTS}

We acknowledge financial support from the EPSRC (Grant No. EP/T001038/1 and EP/P005152/1). P.B.W. acknowledges EPSRC Cambridge NanoDTC Grant No. EP/ G037221/1. O.J.B. acknowledges an EPSRC Doctoral Training Award (EP/M508007/1). R.S.W. acknowledges EU Marie Skłodowska-Curie Individual Fellowship (Global) under grant ARTIST (No. 656870) from the European Union's Horizon 2020 research and innovation programme. We acknowledge the Elettra Sincrotrone Trieste storage ring for provision of synchrotron radiation under proposal 20165323 at the Escamicroscopy beamline and thank the Elettra staff for continuous support of our experiments.

\section{REFERENCES}

(1) Chen, M.; Haddon, R. C.; Yan, R.; Bekyarova, E. Advances in Transferring Chemical Vapour Deposition Graphene: A Review. Mater. Horiz. 2017, 4 (6), 1054-1063.

(2) Banszerus, L.; Schmitz, M.; Engels, S.; Dauber, J.; Oellers, M.; Haupt, F.; Watanabe, K.; Taniguchi, T.; Beschoten, B.; Stampfer, C. Ultrahigh-Mobility Graphene Devices from Chemical Vapor Deposition on Reusable Copper. Sci. Adv. 2015, 1 (6), 1500222.

(3) Wang, Y.; Zheng, Y.; Xu, X.; Dubuisson, E.; Bao, Q.; Lu, J.; Loh, K. P. Electrochemical Delamination of CVD-Grown Graphene Film: Toward the Recyclable Use of Copper Catalyst. ACS Nano 2011, 5 (12), 9927-9933.

(4) Wang, R.; Whelan, P. R.; Braeuninger-Weimer, P.; Tappertzhofen, S.; Alexander-webber, J. A.; Van-veldhoven, Z. A.; Kidambi, P. R.; Jessen, B. S.; Booth, T. J.; Boggild, P.; et al. Catalyst Interface Engineering for Improved 2D Film Lift-Off and Transfer. ACS Appl. Mater. Interfaces 2016, 8 (48), 33072-33082.

(5) Wang, R.; Purdie, D. G.; Fan, Y.; Massabuau, F. C.; BraeuningerWeimer, P.; Burton, O. J.; Blume, R.; Schloegl, R.; Lombardo, A.; Weatherup, R. S.; et al. A Peeling Approach for Integrated Manufacturing of Large Monolayer H-BN Crystals. ACS Nano 2019, 13 (2), 2114-2126.

(6) Giovannetti, G.; Khomyakov, P. A.; Brocks, G.; Karpan, V. M.; Van Den Brink, J.; Kelly, P. J. Doping Graphene with Metal Contacts. Phys. Rev. Lett. 2008, 101 (2), No. 026803.

(7) Giubileo, F.; Di Bartolomeo, A. Progress in Surface Science The Role of Contact Resistance in Graphene Field-Effect Devices. Prog. Surf. Sci. 2017, 92 (3), 143-175.

(8) Hsu, A.; Wang, H.; Kim, K. K.; Kong, J.; Palacios, T. Impact of Graphene Interface Quality on Contact Resistance and RF Device Performance. IEEE Electron Device Lett. 2011, 32 (8), 1008-1010.

(9) Yankowitz, M.; Ma, Q.; Jarillo-Herrero, P.; LeRoy, B. J. van der Waals Heterostructures Combining Graphene and Hexagonal Boron Nitride. Nat. Rev. Phys. 2019, 1 (2), 112-125.

(10) Martin, M. B.; Dlubak, B.; Weatherup, R. S.; Piquemal-Banci, M.; Yang, H.; Blume, R.; Schloegl, R.; Collin, S.; Petroff, F.; Hofmann, S.; et al. Protecting Nickel with Graphene Spin-Filtering Membranes: A Single Layer Is Enough. Appl. Phys. Lett. 2015, 107 (1) No. 012408.

(11) Alexander-Webber, J. A.; Sagade, A. A.; Aria, A. I.; Van Veldhoven, Z. A.; Braeuninger-Weimer, P.; Wang, R.; CabreroVilatela, A.; Martin, M.-B.; Sui, J.; Connolly, M. R.; et al. Encapsulation of Graphene Transistors and Vertical Device Integration by Interface Engineering with Atomic Layer Deposited Oxide. 2D Mater. 2017, 4 (1), No. 011008.

(12) Dlubak, B.; Martin, M.-B.; Weatherup, R. S.; Yang, H.; Deranlot, C.; Blume, R.; Schloegl, R.; Fert, A.; Anane, A.; Hofmann, 
S.; et al. Graphene-Passivated Nickel as an Oxidation- Resistant Spin Polarized Electrode. ACS Nano 2012, 6 (12), 10930-10934.

(13) Banszerus, L.; Janssen, H.; Otto, M.; Epping, A.; Taniguchi, T.; Watanabe, K.; Beschoten, B.; Neumaier, D.; Stampfer, C. Identifying Suitable Substrates for High-Quality Graphene-Based Heterostructures. 2D Mater. 2017, 4 (2), No. 025030.

(14) Akinwande, D.; Huyghebaert, C.; Wang, C.-H.; Serna, M. I.; Goossens, S.; Li, L.-J.; Wong, H.-S. P.; Koppens, F. H. L. Graphene and Two-Dimensional Materials for Silicon Technology. Nature 2019, 573, 507-518.

(15) Li, L.; Chen, X.; Wang, C.; Cao, J.; Lee, S.; Tang, A.; Ahn, C.; Roy, S. S.; Arnold, M. S.; Wong, H. P. Vertical and Lateral Copper Transport through Graphene Layers. ACS Nano 2015, 9 (8), 83618367.

(16) Weatherup, R. S.; D’Arsié, L.; Cabrero-Vilatela, A.; Caneva, S.; Blume, R.; Robertson, J.; Schloegl, R.; Hofmann, S. Long-Term Passivation of Strongly Interacting Metals with Single-Layer Graphene. J. Am. Chem. Soc. 2015, 137 (45), 14358-14366.

(17) Bohm, S. Graphene against Corrosion. Nat. Nanotechnol. 2014, 9 (10), 741-742.

(18) Sutter, P.; Sadowski, J. T.; Sutter, E. A. Chemistry under Cover: Tuning Metal-Graphene Interaction by Reactive Intercalation. J. Am. Chem. Soc. 2010, 132 (23), 8175-8179.

(19) Varykhalov, A.; Sánchez-Barriga, J.; Shikin, A. M.; Biswas, C.; Vescovo, E.; Rybkin, A.; Marchenko, D.; Rader, O. Electronic and Magnetic Properties of Quasifreestanding Graphene on Ni. Phys. Rev. Lett. 2008, 101 (15), 1-4.

(20) Lizzit, S.; Larciprete, R.; Lacovig, P.; Dalmiglio, M.; Orlando, F.; Baraldi, A.; Gammelgaard, L.; Barreto, L.; Bianchi, M.; Perkins, E.; et al. Transfer-Free Electrical Insulation of Epitaxial Graphene from Its Metal Substrate. Suplemmentary Information. Nano Lett. 2012, 12 (9), 4503-4507.

(21) Larciprete, R.; Ulstrup, S.; Lacovig, P.; Dalmiglio, M.; Bianchi, M.; Mazzola, F.; Hornekær, L.; Orlando, F.; Baraldi, A.; Hofmann, P.; et al. Oxygen Switching of the Epitaxial Graphene À Metal Interaction. ACS Nano 2012, 6 (11), 9551-9558.

(22) Grüneis, A.; Vyalikh, D. V. Tunable Hybridization between Electronic States of Graphene and a Metal Surface. Phys. Rev. B: Condens. Matter Mater. Phys. 2008, 77 (19), 193401.

(23) Luo, D.; You, X.; Li, B.-W.; Chen, X.; Park, H. J.; Jung, M.; Ko, T. Y.; Wong, K.; Yousaf, M.; Chen, X.; et al. Role of Graphene in Water-Assisted Oxidation of Copper in Relation to Dry Transfer of Graphene. Chem. Mater. 2017, 29 (10), 4546-4556.

(24) Whelan, P. R.; Jessen, B. S.; Wang, R.; Luo, B.; Stoot, A. C.; Mackenzie, D. M. A.; Braeuninger-Weimer, P.; Jouvray, A.; Prager, L.; Camilli, L.; et al. Raman Spectral Indicators of Catalyst Decoupling for Transfer of CVD Grown 2D Materials. Carbon 2017, 117, 75-81.

(25) Lu, A.-Y.; Wei, S.-Y.; Wu, C.-Y.; Hernandez, Y.; Chen, T.-Y.; Liu, T.-H.; Pao, C.-W.; Chen, F.-R.; Li, L.-J.; Juang, Z.-Y. Decoupling of CVD Graphene by Controlled Oxidation of Recrystallized Cu. RSC Adv. 2012, 2 (7), 3008.

(26) Kang, C. G.; Lim, S. K.; Lee, S.; Lee, S. K.; Cho, C.; Lee, Y. G.; Hwang, H. J.; Kim, Y.; Choi, H. J.; Choe, S. H.; et al. Effects of MultiLayer Graphene Capping on Cu Interconnects. Nanotechnology 2013, 24 (11), 115707.

(27) Li, L.; Wong, H.-S. P. Integrating Graphene into Future Generations of Interconnect Wires. IEEE Int. Electron Devices Meet. 2018, 2018, 5-5.

(28) Chen, S.; Brown, L.; Levendorf, M.; Cai, W.; Ju, S. Y.; Edgeworth, J.; Li, X.; Magnuson, C. W.; Velamakanni, A.; Piner, R. D.; et al. Oxidation Resistance of Graphene-Coated $\mathrm{Cu}$ and $\mathrm{Cu} / \mathrm{Ni}$ Alloy. ACS Nano 2011, 5 (2), 1321-1327.

(29) Schriver, M.; Regan, W.; Gannett, W. J.; Zaniewski, A. M.; Crommie, M. F.; Zettl, A. Graphene as a Long-Term Metal Oxidation Barrier: Worse than Nothing. ACS Nano 2013, 7 (7), 5763-5768.

(30) Prasai, D.; Tuberquia, J. C.; Harl, R. R.; Jennings, G. K.; Bolotin, K. I. Graphene: Corrosion-Inhibiting Coating. ACS Nano 2012, 6 (2), 1102-1108.
(31) Singh Raman, R. K.; Chakraborty Banerjee, P.; Lobo, D. E.; Gullapalli, H.; Sumandasa, M.; Kumar, A.; Choudhary, L.; Tkacz, R.; Ajayan, P. M.; Majumder, M. Protecting Copper from Electrochemical Degradation by Graphene Coating. Carbon 2012, 50 (11), $4040-4045$.

(32) Zhou, F.; Li, Z.; Shenoy, G. J.; Li, L.; Liu, H. Enhanced RoomTemperature Corrosion of Copper in the Presence of Graphene. ACS Nano 2013, 7 (8), 6939-6947.

(33) Zahran, R. R.; Ibrahim, I. H. M.; Sedahmed, G. H. The Corrosion of Graphite/Copper Composites in Different Aqueous Environments. Mater. Lett. 1996, 28 (1-3), 237-244.

(34) Kidambi, P. R.; Bayer, B. C.; Blume, R.; Wang, Z.-J.; Baehtz, C.; Weatherup, R. S.; Willinger, M.-G.; Schloegl, R.; Hofmann, S. Observing Graphene Grow: Catalyst-Graphene Interactions during Scalable Graphene Growth on Polycrystalline Copper. Nano Lett. 2013, 13 (10), 4769-4778.

(35) Blume, R.; Kidambi, P. R.; Bayer, B. C.; Weatherup, R. S.; Wang, Z.-J.; Weinberg, G.; Willinger, M.-G.; Greiner, M.; Hofmann, S.; Knop-Gericke, A.; et al. The Influence of Intercalated Oxygen on the Properties of Graphene on Polycrystalline $\mathrm{Cu}$ under Various Environmental Conditions. Phys. Chem. Chem. Phys. 2014, 16 (47), 25989-26003.

(36) Feng, X.; Maier, S.; Salmeron, M. Water Splits Epitaxial Graphene and Intercalates. J. Am. Chem. Soc. 2012, 134 (12), 56625668.

(37) Kwak, J.; Jo, Y.; Park, S. D.; Kim, N. Y.; Kim, S. Y.; Shin, H. J.; Lee, Z.; Kim, S. Y.; Kwon, S. Y. Oxidation Behavior of GrapheneCoated Copper at Intrinsic Graphene Defects of Different Origins. Nat. Commun. 2017, 8 (1), 1-12.

(38) Jo, M.; Lee, H. C.; Lee, S. G.; Cho, K. Graphene as a Metal Passivation Layer: Corrosion-Accelerator and Inhibitor. Carbon 2017, 116, 232-239.

(39) Xu, Y.; Qu, J.; Shen, Y.; Feng, W. Different Graphene Layers to Enhance or Prevent Corrosion of Polycrystalline Copper. RSC Adv. 2018, 8 (27), 15181-15187.

(40) Xu, X.; Yi, D.; Wang, Z.; Yu, J.; Zhang, Z.; Qiao, R.; Sun, Z.; Hu, Z.; Gao, P.; Peng, H.; et al. Greatly Enhanced Anticorrosion of $\mathrm{Cu}$ by Commensurate Graphene Coating. Adv. Mater. 2018, 30 (6) 1702944.

(41) Gao, L.; Guest, J. R.; Guisinger, N. P. Epitaxial Graphene on $\mathrm{Cu}(111)$. Nano Lett. 2010, 10 (9), 3512-3516.

(42) Rasool, H. I.; Song, E. B.; Allen, M. J.; Wassei, J. K.; Kaner, R. B.; Wang, K. L.; Weiller, B. H.; Gimzewski, J. K. Continuity of Graphene on Polycrystalline Copper. Nano Lett. 2011, 11 (1), 251256.

(43) Zhang, Y.; Gao, T.; Gao, Y.; Xie, S.; Ji, Q.; Yan, K.; Peng, H.; Liu, Z. Defect-like Structures of Graphene on Copper Foils for Strain Relief Investigated by High-Resolution Scanning Tunneling Microscopy. ACS Nano 2011, 5 (5), 4014-4022.

(44) Walter, A. L.; Nie, S.; Bostwick, A.; Kim, K. S.; Moreschini, L.; Chang, Y. J.; Innocenti, D.; Horn, K.; McCarty, K. F.; Rotenberg, E. Electronic Structure of Graphene on Single-Crystal Copper Substrates. Phys. Rev. B: Condens. Matter Mater. Phys. 2011, 84 (19), $1-7$.

(45) Braeuninger-Weimer, P.; Brennan, B.; Pollard, A. J.; Hofmann, $\mathrm{S}$. Understanding and Controlling $\mathrm{Cu}$ Catalyzed Graphene Nucleation: The Role of Impurities, Roughness and Oxygen Scavenging. Chem. Mater. 2016, 28 (24), 8905-8915.

(46) Duong, D. L.; Han, G. H.; Lee, S. M.; Gunes, F.; Kim, E. S.; Kim, S. T.; Kim, H.; Ta, Q. H.; So, K. P.; Yoon, S. J.; et al. Probing Graphene Grain Boundaries with Optical Microscopy. Nature 2012, 490 (7419), 235-239.

(47) Jia, C.; Jiang, J.; Gan, L.; Guo, X. Direct Optical Characterization of Graphene Growth and Domains on Growth Substrates. Sci. Rep. 2012, 2, 707.

(48) Qi, Z.; Zhu, X.; Jin, H.; Zhang, T.; Kong, X.; Ruoff, R. S.; Qiao, Z.; Ji, H. Rapid Identification of the Layer Number of Large-Area Graphene on Copper. Chem. Mater. 2018, 30 (6), 2067-2073. 
(49) Ly, T. H.; Duong, D. L.; Ta, Q. H.; Yao, F.; Vu, Q. A.; Jeong, H. Y.; Chae, S. H.; Lee, Y. H. Nondestructive Characterization of Graphene Defects. Adv. Funct. Mater. 2013, 23 (41), 5183-5189.

(50) Constable, F. H. The Cause of the Colours Shown during the Oxidation of Metallic Copper. Proc. R. Soc. 1927, 117, 376-386.

(51) McAdam, D. J.; Geil, G. W. Rate of Oxidation of Typical Nonferrous Metals as Determined by Interference Colors of Oxide Films. J. Res. Natl. Bur. Stand. (1934) 1942, 28 (5), 593.

(52) Gwathmey, A. T.; Benton, A. F. The Reaction of Gases on the Surface of a Single Crystal of Copper. I: Oxygen. J. Phys. Chem. 1942, 46 (8), 969-980.

(53) Miley, H. A. Copper Oxide Films. J. Am. Chem. Soc. 1937, 59 (3), 2626-2629.

(54) Young, K. T.; Phillips, S. S.; Coley, J. T. T.; Perini, C. J.; Hitchcock, D. A.; Serkiz, S. M.; Vogel, E. M. The Impact of Defect Density, Grain Size, and Cu Orientation on Thermal Oxidation of Graphene-Coated Cu. Appl. Surf. Sci. 2019, 478, 959-968.

(55) Lee, U.; Han, Y.; Lee, S.; Suk, J.; Lee, Y. H.; Kim, U. J.; Son, H. Time Evolutional Studies on Strain and Doping of Graphene Grown on a Copper Substrate Using Raman Spectroscopy. ACS Nano 2020, 14 (1), 919-926.

(56) Scardamaglia, M.; Struzzi, C.; Zakharov, A.; Reckinger, N.; Zeller, P.; Amati, M.; Gregoratti, L. Highlighting the Dynamics of Graphene Protection toward the Oxidation of Copper Under Operando Conditions. ACS Appl. Mater. Interfaces 2019, 11 (32), 29448-29457.

(57) Biesinger, M. C. Advanced Analysis of Copper X-Ray Photoelectron Spectra. Surf. Interface Anal. 2017, 49 (13), 13251334.

(58) Moulder, J.; Stickle, W.; Sobol, P. E.; Bomben, D. K. Handbook of X-Ray Photoelectron Spectroscopy; Perkin-Elmer, 1992.

(59) Platzman, I.; Brener, R.; Haick, H.; Tannenbaum, R. Oxidation of Polycrystalline Copper Thin Films at Ambient Conditions. J. Phys. Chem. C 2008, 112 (4), 1101-1108.

(60) Lee, S. Y.; Mettlach, N.; Nguyen, N.; Sun, Y. M.; White, J. M. Copper Oxide Reduction through Vacuum Annealing. Appl. Surf. Sci. 2003, 206 (1), 102-109.

(61) Weatherup, R. S.; Eren, B.; Hao, Y.; Bluhm, H.; Salmeron, M. B. Graphene Membranes for Atmospheric Pressure Photoelectron Spectroscopy. J. Phys. Chem. Lett. 2016, 7 (9), 1622-1627.

(62) Mohiuddin, T. M. G.; Lombardo, A.; Nair, R. R.; Bonetti, A.; Savini, G.; Jalil, R.; Bonini, N.; Basko, D. M.; Galiotis, C.; Marzari, N.; et al. Uniaxial Strain in Graphene by Raman Spectroscopy: G Peak Splitting, Grüneisen Parameters, and Sample Orientation. Phys. Rev. B: Condens. Matter Mater. Phys. 2009, 79 (20), 1-8.

(63) Lee, J. E.; Ahn, G.; Shim, J.; Lee, Y. S.; Ryu, S. Optical Separation of Mechanical Strain from Charge Doping in Graphene. Nat. Commun. 2012, 3 (1), 1024-1028.

(64) Neumann, C.; Reichardt, S.; Venezuela, P.; Drögeler, M.; Banszerus, L.; Schmitz, M.; Watanabe, K.; Taniguchi, T.; Mauri, F.; Beschoten, B.; et al. Raman Spectroscopy as Probe of NanometreScale Strain Variations in Graphene. Nat. Commun. 2015, 6 (1), 1-7.

(65) Braeuninger-weimer, P.; Burton, O.; Weatherup, R. S.; Wang, R.; Dudin, P.; Brennan, B.; Pollard, A. J.; Bayer, B. C.; Veigangradulescu, V. P.; Meyer, J. C.; et al. Reactive Intercalation and Oxidation at the Buried Graphene-Germanium Interface. APL Mater. 2019, 7 (7), No. 071107.

(66) Luo, B.; Whelan, P. R.; Shivayogimath, A.; Mackenzie, D. M. A.; Boggild, P.; Booth, T. J. Copper Oxidation Through Nucleation Sites of Chemical Vapor Deposited Graphene. Chem. Mater. 2016, 28 (11), 3789-3795.

(67) Wu, R.; Gan, L.; Ou, X.; Zhang, Q.; Luo, Z. Detaching Graphene from Copper Substrate by Oxidation-Assisted Water Intercalation. Carbon 2016, 98 (13382), 138-143.

(68) Li, D. Y.; Li, W. Electron Work Function: A Parameter Sensitive to the Adhesion Behavior of Crystallographic Surfaces. Appl. Phys. Lett. 2001, 79 (26), 4337-4338.
(69) Haas, G. A.; Thomas, R. E. Work Function and Secondary Emission Studies of Various Cu Crystal Faces. J. Appl. Phys. 1977, 48 (1), 86-93.

(70) Godowski, P. J.; Onsgaard, J. Work Function of Vicinal Copper Surfaces. Acta Phys. Pol., A 2013, 123 (1), 115-117.

(71) Derry, G. N.; Kern, M. E.; Worth, E. H. Recommended Values of Clean Metal Surface Work Functions. J. Vac. Sci. Technol., A 2015, 33 (6), No. 060801.

(72) Smoluchowski, R. Anisotropy of the Electronic Workfunction of Metals. Phys. Rev. 1941, 60 (9), 661-674.

(73) Wang, J.; Wang, S. Surface Science Surface Energy and Work Function of Fcc and Bcc Crystals: Density Functional Study. Surf. Sci. 2014, 630, 216-224.

(74) Liang, S. J.; Ang, L. K. Electron Thermionic Emission from Graphene and a Thermionic Energy Converter. Phys. Rev. Appl. 2015, $3(1), 1-8$.

(75) Xu, K.; Zeng, C.; Zhang, Q.; Yan, R.; Ye, P.; Wang, K.; Seabaugh, A. C.; Xing, H. G.; Suehle, J. S.; Richter, C. A.; et al. Direct Measurement of Dirac Point Energy at the Graphene/Oxide Interface. Nano Lett. 2013, 13 (1), 131-136.

(76) Christodoulou, C.; Giannakopoulos, A.; Nardi, M. V.; Ligorio, G.; Oehzelt, M.; Chen, L.; Pasquali, L.; Timpel, M.; Giglia, A.; Nannarone, S.; et al. Tuning the Work Function of Graphene-onQuartz with a High Weight Molecular Acceptor. J. Phys. Chem. C 2014, 118 (9), 4784-4790.

(77) Li, W.; Li, D. Y.; Li, W. On the Correlation between Surface Roughness and Work Function in Copper. J. Chem. Phys. 2005, 122 (6), 064708-6.

(78) Wisniewski, W.; Russel, C. An Experimental Viewpoint on the Information Depth of EBSD. Scanning 2016, 38 (2), 164-171.

(79) Kraus, J.; Böcklein, S.; Reichelt, R.; Günther, S.; Santos, B.; Menteş, T. O.; Locatelli, A. Towards the Perfect Graphene Membrane? - Improvement and Limits during Formation of High Quality Graphene Grown on Cu-Foils. Carbon 2013, 64, 377-390.

(80) Galbiati, M.; Stoot, A. C.; Mackenzie, D. M. A.; Bøggild, P.; Camilli, L. Real-Time Oxide Evolution of Copper Protected by Graphene and Boron Nitride Barriers. Sci. Rep. 2017, 7 (1), 39770.

(81) Camilli, L; Yu, F; Cassidy, A; Hornekær, L; Bøggild, P Challenges for Continuous Graphene as a Corrosion Barrier. $2 D$ Mater. 2019, 6 (2), No. 022002.

(82) Shen, L.; Zhao, Y.; Wang, Y.; Song, R.; Yao, Q.; Chen, S.; Chai, Y. Long-Term Corrosion Barrier with Insulating Boron Nitride Monolayer. J. Mater. Chem. A 2016, 4 (14), 5044-5050.

(83) Bunch, J. S.; Verbridge, S. S.; Alden, J. S.; Van Der Zande, A. M.; Parpia, J. M.; Craighead, H. G.; Mceuen, P. L. Impermeable Atomic Membranes from Graphene Sheets. Nano Lett. 2008, 8 (8), $2458-2462$.

(84) Leenaerts, O.; Partoens, B.; Peeters, F. M. Graphene: A Perfect Nanoballoon. Appl. Phys. Lett. 2008, 93 (19), 193107.

(85) Cancado, L. G.; Jorio, A.; Ferreira, E. H. M.; Stavale, F.; Achete, C. A.; Capaz, R. B.; Moutinho, M. V. O.; Lombardo, A.; Kulmala, T. S.; Ferrari, A. C. Quantifying Defects in Graphene via Raman Spectroscopy at Different Excitation Energies. Nano Lett. 2011, 11 (8), 3190-3196.

(86) Deng, B.; Wu, J.; Zhang, S.; Qi, Y.; Zheng, L.; Yang, H.; Tang, J.; Tong, L.; Zhang, J.; Liu, Z.; Peng, H. Anisotropic Strain Relaxation of Graphene by Corrugation on Copper Crystal Surfaces. Small 2018, 14 (22), 1800725.

(87) Kang, J. H.; Moon, J.; Kim, D. J.; Kim, Y.; Jo, I.; Jeon, C.; Lee, J.; Hong, B. H. Strain Relaxation of Graphene Layers by $\mathrm{Cu}$ Surface Roughening. Nano Lett. 2016, 16 (10), 5993-5998.

(88) Tian, J.; Cao, H.; Wu, W.; Yu, Q.; Guisinger, N. P.; Chen, Y. P. Graphene Induced Surface Reconstruction of Cu. Nano Lett. 2012, 12 (8), 3893-3899.

(89) Hattab, H.; N’Diaye, A. T.; Wall, D.; Klein, C.; Jnawali, G.; Coraux, J.; Busse, C.; Van Gastel, R.; Poelsema, B.; Michely, T.; et al. Interplay of Wrinkles, Strain, and Lattice Parameter in Graphene on Iridium. Nano Lett. 2012, 12 (2), 678-682. 
(90) Deng, S.; Berry, V. Wrinkled, Rippled and Crumpled Graphene: An Overview of Formation Mechanism, Electronic Properties, and Applications. Mater. Today 2016, 19 (4), 197-212.

(91) Kojima, R.; Susa, M. Surface Melting of Copper with (100), (110), and (111) Orientations in Terms of Molecular Dynamics Simulation. High Temp. - High Pressures 2002, 34 (6), 639-648.

(92) Zhang, Y. H.; Wang, B.; Zhang, H. R.; Chen, Z. Y.; Zhang, Y. Q.; Wang, B.; Sui, Y. P.; Li, X. L.; Xie, X. M.; Yu, G. H.; et al. The Distribution of Wrinkles and Their Effects on the Oxidation Resistance of Chemical Vapor Deposition Graphene. Carbon 2014, $70,81-86$.

(93) Hakkinen, H.; Manninen, M. Computer Simulation of Disordering and Premelting of Low-Index Faces of Copper. Phys. Rev. B: Condens. Matter Mater. Phys. 1992, 46 (3), 1725.

(94) Platzman, I.; Saguy, C.; Brener, R.; Tannenbaum, R.; Haick, H. Formation of Ultrasmooth and Highly Stable Copper Surfaces through Annealing and Self-Assembly of Organic Monolayers. Langmuir 2010, 26 (1), 191-201.

(95) Yamamoto, S.; Bluhm, H.; Andersson, K.; Ketteler, G.; Ogasawara, H.; Salmeron, M.; Nilsson, A. In Situ X-Ray Photoelectron Spectroscopy Studies of Water on Metals and Oxides at Ambient Conditions. J. Phys.: Condens. Matter 2008, 20 (18), 184025.

(96) Gattinoni, C.; Michaelides, A. Atomistic Details of Oxide Surfaces and Surface Oxidation: The Example of Copper and Its Oxides. Surf. Sci. Rep. 2015, 70 (3), 424-447.

(97) Liu, T.; Chen, S.; Cheng, S.; Tian, J.; Chang, X.; Yin, Y. Corrosion Behavior of Super-Hydrophobic Surface on Copper in Seawater. Electrochim. Acta 2007, 52 (28), 8003-8007.

(98) Mohamed, A. M. A.; Abdullah, A. M.; Younan, N. A. Corrosion Behavior of Superhydrophobic Surfaces: A Review. Arabian J. Chem. 2015, 8 (6), 749-765.

(99) Tasic, Z. Z.; Petrovic Mihajlovic, M. B.; Radovanovic, M. B.; Antonijevic, M. M. New Trends in Corrosion Protection of Copper. Chem. Pap. 2019, 73 (9), 2103-2132.

(100) Lee, D.; Ahn, G.; Ryu, S. Two-Dimensional Water Diffusion at a Graphene - Silica Interface. J. Am. Chem. Soc. 2014, 136, 66346642 .

(101) Lawton, T. J.; Pushkarev, V.; Broitman, E.; Reinicker, A.; Sykes, E. C. H.; Gellman, A. J. Initial Oxidation of $\mathrm{Cu}(\mathrm{Hkl})$ Surfaces Vicinal to $\mathrm{Cu}(111)$ : A High-Throughput Study of Structure Sensitivity. J. Phys. Chem. C 2012, 116 (30), 16054-16062.

(102) Wiame, F.; Maurice, V.; Marcus, P. Initial Stages of Oxidation of $\mathrm{Cu}\left(\begin{array}{lll}1 & 1 & 1\end{array}\right)$. Surf. Sci. 2007, 601 (5), 1193-1204.

(103) Armitage, A. F.; Woodruff, D. P. Initial Adsorption Kinetics of Oxygen and Sulphur on Copper Cylindrical Crystal Surfaces. Surf. Sci. 1982, $114(2-3), 414-430$.

(104) Matsumoto, T.; Bennett, R. A.; Stone, P.; Yamada, T.; Domen, K.; Bowker, M. Scanning Tunneling Microscopy Studies of Oxygen Adsorption on $\mathrm{Cu}(111)$. Surf. Sci. 2001, 471 (1-3), 225245.

(105) Tseng, C.; Tu, K. N.; Chen, C. Comparison of Oxidation in Uni-Directionally and Randomly Oriented $\mathrm{Cu}$ Films for Low Temperature Cu-to-Cu Direct Bonding. Sci. Rep. 2018, 8 (1), 1-7.

(106) Jeon, B.; Sankaranarayanan, S. K.R.S.; van Duin, A. C.T.; Ramanathan, S. Influence of Surface Orientation and Defects on Early-Stage Oxidation and Ultrathin Oxide Growth on Pure Copper. Philos. Mag. 2011, 91 (32), 4073-4088.

(107) Keil, P.; Lutzenkirche-Hecht, D.; Frahiri, R. Investigation of Room Temperature Oxidation of $\mathrm{Cu}$ in Air by Yoneda-XAFS. AIP Conf. Proc. 2006, 882 (1), 490-492.

(108) Zhang, H.; Ren, S.; Pu, J.; Xue, Q. Barrier Mechanism of Multilayers Graphene Coated Copper against Atomic Oxygen Irradiation. Appl. Surf. Sci. 2018, 444, 28-35.

(109) Wu, M.; Zhang, Z.; Xu, X.; Zhang, Z.; Duan, Y.; Dong, J.; Qiao, R.; You, S.; Wang, L.; Qi, J.; et al. Seeded Growth of Large Single-Crystal Copper Foils with High-Index Facets. Nature 2020, 581 (7809), 406-410.

(110) Huang, P. Y.; Ruiz-Vargas, C. S.; van der Zande, A. M.; Whitney, W. S.; Levendorf, M. P.; Kevek, J. W.; Garg, S.; Alden, J. S.;
Hustedt, C. J.; Zhu, Y.; et al. Grains and Grain Boundaries in SingleLayer Graphene Atomic Patchwork Quilts. Nature 2011, 469 (7330), 389-392.

(111) Fauzi, F. B.; Ismail, E.; Ani, M. H.; Syed Abu Bakar, S. N.; Mohamed, M. A.; Majlis, B. Y.; Md Din, M. F.; Azam Mohd Abid, M. A. A Critical Review of the Effects of Fluid Dynamics on Graphene Growth in Atmospheric Pressure Chemical Vapor Deposition. J. Mater. Res. 2018, 33 (9), 1088-1108.

(112) Wood, J. D.; Schmucker, S. W.; Lyons, A. S.; Pop, E.; Lyding, J. W. Effects of Polycrystalline Cu Substrate on Graphene Growth by Chemical Vapor Deposition. Nano Lett. 2011, 11 (11), 4547-4554.

(113) Gregoratti, L.; Al-Hada, M.; Amati, M.; Brescia, R.; Roccella, D.; Sezen, H.; Zeller, P. Spatially Resolved Photoelectron Spectroscopy from Ultra-High Vacuum to Near Ambient Pressure Sample Environments. Top. Catal. 2018, 61 (12-13), 1274-1282.

(114) Gregoratti, L.; Barinov, A.; Benfatto, E.; Cautero, G.; Fava, C.; Lacovig, P.; Lonza, D.; Kiskinova, M.; Tommasini, R.; Mähl, S.; et al. 48-Channel Electron Detector for Photoemission Spectroscopy and Microscopy. Rev. Sci. Instrum. 2004, 75 (1), 64-68. 